\title{
What Do We Know About Youth Softball Pitching and Injury?
}

\author{
Jeff Barfield and Gretchen Oliver *i)
}

\begin{abstract}
Participation rates in fastpitch softball are continually on the rise, especially in youth. With the increased participation also comes the increased injury susceptibility. Unfortunately, the common misconception about the dynamic $360^{\circ}$ windmill softball pitch, that it is a natural motion and thus does not cause stress on the shoulder, deterred investigation into pitching mechanics until recently. As pitching injuries in softball are on the rise, more attention is needed into the mechanics of the windmill softball pitch and injury implications. Therefore, it was the purpose of this current opinion paper to shed light on what is known about youth softball pitching and injury susceptibility.
\end{abstract}

Keywords: Fastpitch, Injury, Pitching, Softball, Windmill

\section{Keypoints}

- With the increased popularity of fastpitch softball, awareness is needed on the physical demands of the windmill softball motion that relate to injury.

- Windmill softball pitchers are subject to fatigue that affects their mechanics and could potentially alter their injury susceptibility.

The windmill softball pitch is a dynamic movement that requires an athlete to rapidly move their pitching arm in a full $360^{\circ}$ circular motion. However, a common misconception is that the windmill softball pitch produces less force on the shoulder and elbow in comparison to overhand pitching. Due to this fallacy, a lack of focus on windmill softball pitching and injury susceptibility exists among researchers, clinicians, and coaches. Since the windmill softball pitch is a dynamic motion that occurs at maximal effort due to the competitive nature of the sport, pitchers are subject to high joint loads and subsequent increased predisposition towards injury. Because of the competitive nature and increased population of the sport of softball, there has been an increased awareness regarding injury susceptibility, and

\footnotetext{
* Correspondence: goliver@auburn.edu;

https://www.sportsmedicineandmovement.com

Sports Medicine and Movement Lab, School of Kinesiology, Auburn

University, 301 Wire Rd, Auburn, AL 36849, USA
}

anecdotally, orthopedic surgeons report an increase in diagnosed upper extremity injury for softball athletes.

Among all ages of youth, softball participation rates are on the rise. Approximately 260,000 athletes participate in Little League softball [1]. From 2014 to 2015 through 2016-2017, high school softball showed an increase from 365,528 to 368,734 athletes, respectively [2]. Additionally, participation in softball has approached that of baseball [2]. An analogous trend in injury rate exists between softball and baseball [3], with a majority of these injuries being overuse in nature. Paradoxical to the increase in participation, research regarding softball pitching mechanics and injury prevention is scarce. By raising awareness of proper mechanics, physical demands of the game, and injury propensity through attention to detail, researchers and clinicians can help create a safer playing environment for softball athletes of all ages.

\section{Biomechanics of the Softball Pitch}

While literature covering baseball research greatly surpasses softball research, several studies have revealed that the windmill softball pitch generates similar forces about the shoulder as those experienced in overhand pitching $[4,5]$. Because of these and other biomechanical similarities seen between baseball and softball, researchers and clinicians should draw on the known to help clarify the unknown about softball. Barrentine et al. [4] found that in the first half of the windmill pitch, the
SpringerOpen

(c) The Author(s). 2018 Open Access This article is distributed under the terms of the Creative Commons Attribution 4.0 International License (http://creativecommons.org/licenses/by/4.0/), which permits unrestricted use, distribution, and reproduction in any medium, provided you give appropriate credit to the original author(s) and the source, provide a link to the Creative Commons license, and indicate if changes were made. 
shoulder reached a maximum adduction and internal rotation torque as well as a maximum angular velocity of greater than $5,000^{\circ} / \mathrm{s}$ as the arm was approaching the top of back swing. Additionally, during the latter half of the delivery phase of the windmill softball pitch, the elbow reached a maximum compressive force of $70 \%$ of body weight as well as a maximum extension angular velocity of $570^{\circ} / \mathrm{s}$. With similar joint loads found for the overhand and windmill pitching motion $[4,5]$, coaches and sports medicine professionals need to delve further into the investigation of why such a difference in performance demands exists between baseball and softball.

\section{Pitching Exposure}

Recently, the performance demands of softball have been questioned in relation to injury propensity [6-9]. A major difference between the management of baseball and softball pitchers relates to the size of pitching staffs. Where a baseball pitching staff will make up half of the team with as many as 17 , a softball pitching staff could include as few as one with a maximum of four [7]. In 2015, researchers concluded that the sport of softball carries a high incidence of injury, after an examination of 48 pitchers and 50 position players over the course of a season [9]. Most injuries reported within the season were not related to pitching; however, of the pitching injuries observed, more than $60 \%$ of them were to the shoulder [9]. Also considering the pitching injuries seen in that study, a majority of them occurred at the beginning of the season. Thus, the researchers concluded that softball pitching may not be as safe as it has previously been assumed. Although many factors influence an athlete's injury susceptibility, these early season injuries observed in this study suggest more evidence of overuse of a dynamic system.

An examination of softball pitchers (14-18 years) during a 2- to 3-day tournament revealed that on average pitchers threw 1.5 games per day, 82 pitches per day for an average total of 166 pitches during the competition [8]. In this study, researchers investigated subjective measures of pain and fatigue, and they found both pain and fatigue increased from day one to day three of tournament play. Additionally, eight of nine upper extremity strength test performances decreased over the course of the weekend tournament. In another examination of fatigue and pain as well as strength and range of motion in high school softball pitchers, Yang et al. found that within 6 weeks the pitchers averaged $12 \pm 5.7$ games, threw an average of $89 \pm 25$ pitches per game, had decreased shoulder strength, and reported increased pain and fatigue [10]. In another study examining pitching a single game, researchers reported that softball pitchers $15 \pm 1.2$ years, threw on average $99 \pm 21$ pitches and experienced profound fatigue in their hip and scapula musculature following a single bout of pitching [6]. Based on these studies, clinicians, coaches, and researchers should not be surprised that softball pitchers are subject to fatigue and should set parameters around the sport of softball to help protect these athletes.

\section{Injuries in Pitchers}

The findings of the aforementioned studies, in addition to the fact that a study of collegiate and high school fast pitch softball players from 2004 to 2009 reported approximately 370 overuse injuries [11], question the notion of why pitching restrictions have not been imposed. In a study examining rate of injuries in softball, Hill et al. [12] reported that $72.8 \%$ of the examined softball pitchers suffered injury, of which 55\% involved the shoulder. In an earlier study, Loosli et al. [13] reported pitchers sustained $65 \%$ of their injuries to the upper extremity with $52.9 \%$ occurring at the shoulder. Until recently, research bypassed the relationship between kinematic data and pain history in youth and collegiate softball athletes. Softball pitching kinematic data have previously been limited to three studies $[5,14,15]$. Perhaps more research in this area will help clinicians and coaches establish pitch count guidelines for the sport of softball that are similar to those in baseball.

Analysis of collegiate pitchers over a single game found that a collegiate softball pitcher's average pitch count was $179 \pm 45$ [7]. To contrast this with overhand pitching, males aged 19-22 are recommended to pitch no more than 120 pitches a day with 5 days' rest in between outings [16]. Following a bout of this volume of softball pitching, pitchers were found to have significant decreases in hip and shoulder isometric strength but no decrease in range of motion. The decreases in isometric strength provide evidence of fatigue in the pelvic and scapular stabilizers. Given this finding, coaches and sports medicine professionals need to remember that when a muscle is fatigued, a synergist will have to take up an additional job, leading to stabilizer fatigue and overuse injury. Further investigation over a collegiate season revealed no significant differences in hip or shoulder range of motion or strength over the course of the season [7].

With the aforementioned studies reporting pain and fatigue following not only extended but acute bouts of pitching, Oliver et al. [17] examined collegiate pitchers' pain history and pitching mechanics. The authors concluded that those with upper extremity pain have significantly different mechanics than those found to be pain free. Specifically, those with upper extremity pain displayed greater shoulder horizontal abduction at foot contact and less trunk flexion to the throwing side at ball release than the pain-free group. Furthermore, the upper extremity pain group displayed greater shoulder distraction forces at ball release. Not surprisingly, 
alterations in windmill pitching mechanics can alter joint kinetics which will indirectly affect injury potential for a softball pitcher.

\section{Conclusions}

This review of literature on youth softball shows that fatigue has significant implications for softball pitchers. Sports medicine professionals know that fatigue will place athletes in compromising biomechanical positions. The fact that the windmill motion is a dynamic, competitive motion does not make it exempt. Janes and colleagues found that pitchers will use biomechanical compensations to maintain a competitive ball velocity [18]. The increased participation and injury rate for softball is clear. Clinicians and softball organizations need to answer the push for early specialization with pitch count limitations, such as those issued by Stop Sports Injuries [19], to offset the adverse effects of fatigue in youth softball pitchers.

\section{Acknowledgements}

Not applicable.

\section{Funding}

Not applicable, there was no funding source.

\section{Availability of Data and Materials}

Not applicable.

\section{Authors' Contributions}

GO conceived the concept, outline of the review topic, interpreted the literature available, and drafted and edited the manuscript. JB interpreted the literature available and drafted and edited the manuscript. Both authors have read and approved the final version of the manuscript and agree with the order of presentation of the authors.

\section{Competing Interest}

The authors, Jeff Barfield and Gretchen Oliver, declare that they have no competing interests.

\section{Ethics Approval and Consent to Participate}

Not applicable.

\section{Consent for Publication}

Not applicable.

\section{Publisher's Note}

Springer Nature remains neutral with regard to jurisdictional claims in published maps and institutional affiliations.

Received: 20 July 2018 Accepted: 31 October 2018

Published online: 19 November 2018

\section{References}

1. Little League Softball (2018) Little League Softball Europe \& Africa Overview. Accessed October 9, 2018. Avaliable from: https://www.littleleague.org/playlittle-league/softball/europe-africa/

2. National Federation of State High School Associations. 2016-2017 high school athletics participation survey. In: Participation Statistics; 2017. p. 1-19.

3. Pytiak AV, Kraeutler MJ, Currie DW, et al. An epidemiological comparison of elbow injuries among United States high school baseball and softball players, 2005-2006 through 2014-2015. Sports Health. 2017:10:119-24.

4. Barrentine SW, Fleisig GS, Whiteside JA, et al. Biomechanics of windmill softball pitching with implications about injury mechanisms at the shoulder and elbow. J Orthop Sports Phys Ther. 1998;28:405-15.
5. Werner SL, Jones DG, Guido JA Jr, et al. Kinematics and kinetics of elite windmill softball pitching. Am J Sports Med. 2006;34:597-603.

6. Corben JS, Cerrone SA, Soviero JE, et al. Performance demands in softball pitching: a comprehensive muscle fatigue study. Am J Sports Med. 2015;43: 2035-41.

7. Oliver GD, Washington JK, Friesen KB, et al. The effects of a pre-throwing program on collegiate NCAA Division I softball pitchers' biomechanical measures of hip and shoulder range of motion. J. Ortho. Res.Ther. 2018;181. https://doi.org/10.29011/2575-8241.

8. Skillington SA, Brophy RH, Wright RW, et al. Effect of pitching consecutive days in youth fast-pitch softball tournaments on objective shoulder strength and subjective shoulder symptoms. Am J Sports Med. 2017:45:1413-9.

9. Smith MV, Davis $\mathrm{R}$, Brophy $\mathrm{RH}$, et al. Prospective player-reported injuries in female youth fast-pitch softball. Sports Health. 2015;7:497-503.

10. Yang JS, Stepan JG, D'voracek $L$, et al. Fast-pitch softball pitchers experience a significant increase in pain and fatigue during a single high school season. HSS J. 2016:12:111-8.

11. Roos KG, Marshall R, Kerr ZY, Golightly YM, Kucera KL, Myers JB et al. Epidemology of overuse injuries in collegiate and high school athletics in the United States. Am J Sports Med. 2015:43(7):1790-7.

12. Hill JL, Humphries B, Weidner $T$, et al. Female collegiate windmill pitchers: influences to injury incidence. J Strength Cond Res. 2004;18:426-31.

13. Loosli AR, Requa RK, Garrick JG, et al. Injuries to pitchers in women's collegiate fast-pitch softball. Am J Sports Med. 1992;20:35-7.

14. Oliver GD, Dwelly PM, Kwon YH. Kinematic motion of the windmill softball pitch in prepubescent and pubescent girls. J. Strength Cond. Res. 2010;24:2400-7.

15. Werner SL, Guido JA, Mcneice RP, et al. Biomechanics of youth windmill softball pitching. Am J Sports Med. 2005;33:552-60.

16. Baseball ML. Pitch Smart. Major League Baseball. http://m.mlb.com/ pitchsmart. Accessed 5 July 2018.

17. Oliver GD, Gilmer G, Anz AW, et al. Upper extremity pain and pitching mechanics in NCAA division I softball. Int J Sports Med. 2018. https://doi. org/10.1055/a-0658-1546.

18. Janes W, Foreman M, Engsberg JR, et al. Fast-pitch softball players use biomechanical compensations to maintain pitch speed when fatiqued. Am. J. Occup. Ther. 2017;71, 711500037p1. https://doi.org/10.5014/ajot.2017.71s1-PO3147.

19. American Orthopaedic Society for Sports Medicine (2017) Stop sport injuries. Accessed October 9, 2018. Avaliable from: https://www. stopsportsinjuries.org

\section{Submit your manuscript to a SpringerOpen ${ }^{\circ}$ journal and benefit from:}

- Convenient online submission

- Rigorous peer review

- Open access: articles freely available online

- High visibility within the field

- Retaining the copyright to your article

Submit your next manuscript at $>$ springeropen.com 